\title{
SANTO DOMINGO DE SILOS, REDENTOR DE CAUTIVOS, Y UNAS GALLINAS DE BERBERÍA
}

\author{
Miguel C. Vivancos \\ Doctor en Historia \\ mvivancos@yahoo.com
}

Resumen: Santo Domingo de Silos (muerto en 1073) fue invocado como redentor de cautivos cristianos, que estaban en manos de los moros. Algunos de sus milagros suceden en el norte de África. Uno de ellos, reelaborado desde el siglo XV, explica la presencia en Silos de unas gallinas de raza especial. El milagro del moro y el arca fue atribuido también a la Virgen en algunos santuarios marianos.

Palabras Clave: Santo Domingo de Silos, cautivos cristianos, gallinas.

Abstract: St Dominic of Silos (†1073) was invoked as the rescuer of Christian captives held in Muslim lands. Some of his miracles take place in North Africa. One of which, re-elaborated since the fiteenth century, explains how a special breed of hen came to be kept in Silos. The miracle of the Muslim and the treasure-chest was also attributed to the Virgin in some Marian sanctuary-collections.

Keywords: St Dominic of Silos, Christian captives, hen.

\section{Introducción}

Santo Domingo de Silos fue un santo que gozó desde su muerte, en 1073, de fama de gran taumaturgo, especializado, por así decir, en la liberación de cautivos cristianos que yacían en las mazmorras de la España musulmana e incluso en el norte de África ${ }^{1}$. Sabemos de su vida por un contemporáneo suyo, que nos dejó una Vita latina, en la que ya se recogen milagros de cautivos, pero un monje del siglo XIII, llamado Pero Marín, escribió unos Miráculos romançados, cuyos protagonistas son en su práctica totalidad cautivos ${ }^{2}$ cristianos en tierra

Sobre este santo hemos escrito en varias ocasiones, pero para lo que sigue véase especialmenteVivancos, 2003 y Vivancos, 2011a.

2 Editada y traducida por Valcárcel, 1982. 
de moros ${ }^{3}$. Entre otros, cuenta cómo el 5 de mayo de 1285 llegó Gil Pérez al monasterio de Santo Domingo de Silos y allí, en el claustro, ante el convento reunido, dijo que por intercesión de Santo Domingo se había visto libre del cautiverio al que los moros le tenían sometido en Granada, junto con otro cristiano, de nombre Martín. Además de narrar su caso, relató a los monjes el de otro cautivo cristiano, tal como él lo oyera a su señor:

Et dixo este Gil Pérez que él e Martín, yaziendo catiuos en Granada, que oyera dezir a su sennor quel tenía preso, quel dizían Muça Barrabarach, que auía en Granada un moro que auía nonbre Aboaçan, que auía conprados XII cristianos catiuos; e assí como los conpraua que gelos leuaua Santo Domingo uno a uno. Et diz que conpró otro cristiano quel dizían Domingo Pérez de Xodar, e quel metió en grandes fierros, e metiol en una archa grant, e foradóla yuso en el suelo e sacó los fierros por yuso del archa e metiólos en una algorfa, e atólos yuso con una cadena a una estaca de fierro. Et otro día aquel moro auía de fazer bodas, e auía puesto con sus parientes que matasse e descabeçasse aquel cristiano que tenía catiuo por alma de su padre e de su madre. Yaziendo el cristiano dentro en el archa bien recapdado e la arca çerrada con buena laue, el moro echósse sobrel arca en la noche. Et dixo quando se echó en algarauía: «Métolo en soberuia a Santo Domingo, que non me lieue esta noche este catiuo como los otros XII catiuos que me a leuado». Echósse, adurmiós sobre el arca. Otro día amanesçió el moro sobre su arca e el cristiano dentro en ella con sus fierros e con la cadena en Priego, castiello de los freyres de Calatraua. Esto contó Gil Pérez sobredicho en la claustra de Santo Domingo antel conuento, que assí lo oyera dezir muchas uezes en Granada (Anton, 1988, pp. 119-120).

Tenemos aquí, pues, el primer testimonio de un milagro obrado por Santo Domingo de Silos, redentor de cautivos, en el que un cristiano encerrado en un arca, cargado de hierros, es llevado a tierra de cristianos de forma prodigiosa con el arca, las cadenas y el moro, su señor, que para más seguridad dormía sobre el arca. Retengamos un detalle importante: amanecen todos en Priego, no en el monasterio, como hubiera sido lo esperable, pues a él se dirigían todos los cautivos

Edición de Anton, 1988. Sobre el autor, véase Vivancos, 2012. 
liberados por la intercesión milagrosa del Santo, y en él daban su testimonio ante los monjes y el pueblo fiel.

Hacia el año 1400, antes de contar con una nueva forma escrita del portento, se pintó el mismo en un frontal de altar de procedencia aragonesa o navarra, pero con detalles que no figuran en Pero Marín, ya que sobre el arca dormita un moro acompañado de un gallo, y junto a ella está recostado un perro. Además, en lugar de uno son dos los cautivos ${ }^{4}$. El relato de los Miráculos romançados no permite por sí solo comprender estos añadidos, que habrán de explicarse a la luz de textos más tardíos. La primera reelaboración escrita lo fue en el siglo XVII gracias a la pluma de un monje de Silos, Gaspar Ruiz de Montiano, quien entre 1613-1615 compuso una Historia milagrosa de Santo Domingo de Silos, que se conserva manuscrita en el archivo de Silos 5 . Su obra demuestra un agudo sentido crítico para su época, y de ella se aprovecharon los biógrafos posteriores de Santo Domingo de Silos. He aquí el texto del milagro reelaborado, que sigue inmediatamente al contado por Gil Pérez:

Esto contó Gil Pérez delante de la mayor parte del conuento de Santo Domingo, y no dice más la historia de qué se hiço el moro ni el arca, pero algunos an querido mezclar el suceso deste milagro con otro semejante a él en algo. Y para que cada cosa vaya por su parte, diré lo [que] entiendo acerca desto.

En el monasterio de Santo Domingo de Silos se van conserando y criando vna casta de gallinas blancas, que se tienen por su parte fuera del corral de las otras gallinas ordinarias y dentro de la clausura del monasterio con vn aposentico en el claustro bajo que sirue de dormitorio donde ellas se recogen. Y andan tan domésticas y familiares con los religiosos de la casa que jamás salen del claustro della, y en tañendo la campana a comer y cenar son tan ciertas en el refectorio como los monges. Esta casta de gallinas (según certísima tradición del monasterio) tray su origen de vn gallo y vna gallina que se hallaron en vn milagro de nuestro glorioso Padre Santo Domingo, y por este respeto se tiene tanto cuydado en aquella casa de conseruar este linage de gallinas.

Cómo aya sucedido este milagro no será fácil de decir quanto a

Gutiérrez, 2003, pp. 481-483.

Sobre esta obra véase lo dicho en Vivancos, 2003, p. 226. Se conserva en el archivo del monasterio de Silos (AMS), ms. 21. 
todas sus circunstancias, aunque en la sustancia dél no podremos errar. La causa de no tener entera noticia deste suceso es que cierta persona, aborrecida de que los prelados de aquella casa le mandaban muchas veces trasladar este milagro de vn libro antiguo en que están otros muchos, rompió las ojas donde este milagro estaba escrito, y ansí nos dexó a ciegas; y por tener alguna semejanza con el que acabamos de referir, confunden algunos el vno con el otro.

En sustancia pasó ansí: que cierto moro tenía otro captiuo que le estimaba en mucho, porque era hombre de habilidad para ganar cada día a su amo dinero y otros intereses; y como todos los moros en aquel tiempo viuían con temor de los asaltos que el glorioso Santo Domingo les hacía, lleuándolos los cautivos, determinó este moro de ponelle muy cerca de sí a las noches. Y porque tenía pesado el sueño, y le pareció que si Santo Domingo venía a llevarle el cautiuo no le sentiría, puso vn gallo y vna gallina a su cabezera, con pensamiento de que si venía alguien por el cautiuo, que con el ruydo y alboroto que hacen estas aues quando ven persona a desora, le despertarían y guardaría su cautiuo. Algunos dicen que le metió dentro de vna arca de piedra y se acostó sobre ella, poniendo el gallo y la gallina sobre ella; y se va con esta tradición en el monasterio y tienen allí cierta arca grande de piedra, en que agora está el cuerpo del obispo de Sidonia en el crucero de la yglesia, a la parte de la epístola junto a la puerta de la sacristía nueua; de lo qual no tengo más luz de la que se dice de palabra, y puede ser que sea esto lo que estaba escrito en las ojas que rompió aquel religioso, que aunque merecía nombrarse por auer sido insigne escribano en todo género de formas, no le nombro por auer executado su impaciencia tan a costa de las marauillas de nuestro Santo.

En resolución, séase arca o sea cama o otra qualquiera cosa la que el moro escogió para acomodarse con el cautiuo y el gallo y la gallina que le despertasen, lo que pasó es que todo ello originalmente, el moro, el cautiuo, las aues, el arca (si lo era), amanecieron dentro de la yglesia del monasterio de Santo Domingo de Silos, y como el moro oyese tañer la campana que llama a los religiosos al oficio diuino por la mañana, despertó diciendo: "¿Qué zenzerros son estos?» Y poco a poco fue despauilando los ojos y se halló en la yglesia y comenzó a dar voces hasta que bajaron monges, que como estaban tan acostumbrados cada día a ver 
milagros de su Santo, no se les hacía cosa nueua. Y hallaron su moro atónito, y sacaron su cautiuo con las prisiones, y recogieron el gallo y la gallina, que se van conseruando oy día en el monasterio para perpetua memoria deste suceso y para honrra de Dios y de Santo Domingo.

Algunos preuendados de la yglesia de Santo Domingo de la Calzada en Rioja piensan que el gallo y la gallina que se conserua en Santo Domingo de Silos es hurtado de otras gallinas que se crían y guardan también en aquella santa yglesia catedral suya, en memoria de otro famoso milagro que sucedió con Santo Domingo de la Calzada, y yo soy testigo de las quexas que alguno dellos formó en mi presencia desto; y aunque entonces juzgué que no conuenía dar satisffación a esto, porque me pareció que no la pedía el tiempo ni el lugar donde estábamos, agora se podrá satisffacer con lo referido aquí si bastare, y si no, no ay nada perdido, pues no es caso de inquisición el creer esto o no lo creer, aunque no se a de pensar que no puede Dios seruirse de gallinas para más de vn milagro. Que como se siruió del cuerbo para dar de comer a Elías en el desierto milagrosamente, y después quiso que también el cueruo lleuase el pan empozoñado que le arrojó el patriarca de las religiones, San Benito, para que lo pusiese donde no hiciese daño a nadie (como lo cuenta San Gregorio Magno), ansí mesmo pudo seruirse de las gallinas para vn milagro de Santo Domingo de la Calzada y después aprouecharse dellas para otro de Santo Domingo de Silos (AMS, ms. 21, fols. 100-101).

Por mucho que diga el Padre Ruiz de Montiano, da la impresión de que el milagro por él contado no es sino una reelaboración del que trae Pero Marín, y que en su tiempo, y al menos desde el siglo XV (a juzgar por lo pintado en el frontal), corría ya en el monasterio para explicar la presencia de unas gallinas poco comunes. Es ingeniosa, pero poco creíble, la explicación de la pérdida de los folios donde se contaba el portento. En cambio, si las gallinas no fueron robadas en Santo Domingo de la Calzada, la idea de vincular una raza especial de gallinas con un milagro sí que puede proceder del santuario riojano, donde, además del famoso prodigio de la gallina, que cantó después de asada, se contaba otro caso similar, pero con un moro y un cautivo de protagonistas:

Prendieron los moros a vn mancebo de Rioja, y pusiéronle preso en vna obscura mazmorra, donde padeció por espacio de muchos días. Encomendávasse continuamente a nuestro Santo como buen 
riojano, rogándole con gran fe le librasse de aquella penosa cárcel, como lo avía executado con otros muchos sus devotos; y esto lo repetía con tan clara vozes que lo oían las guardas que le asistían. El moro, dueño de este cautivo, combidó vn día a comer a otros amigos moros, y entre otras cosas se puso en la mesa un gallo assado. Servía vno de los guardas del cautivo a la mesa y, hablándose del preso, dixo: «Mucho temo, señor, según lo mucho que este christiano llama en su favor a vn Santo Domingo de la Calzada, que nos le ha de sacar de las prisiones el Santo que dizen haze muchos prodigios». Rióse el moro y con gran satisfacción le respondió: «Si tú le tienes preso de la suerte que yo poco ha le dexé, assí podrá él soltar de las prisiones como este gallo assado y a punto de trincharse puede levantarse y cantar». Apenas acabó de pronunciar estas palabras quando el gallo se vistió de plumas blancas, se levantó y empezó a cantar sobre el plato. Assombráronse todos, y dando por cierta la liberación del cautivo baxaron a registrar el calabozo y le hallaron vacío, sin el preso y lleno de luz y resplandor de el cielo, porque al mismo tiempo que resucitó el gallo se apareció Santo Domingo en la cárcel, soltó al preso, sacóle del calabozo y el cautivo libre se fue a Santo Domingo de la Calzada, y en la rexa de nuestro Santo colgó las cadenas, que para este efecto se llevó consigo (González Texada, 1702, p. 234).

Aunque las circunstancias del milagro son diferentes, es evidente que hay relación entre Santo Domingo de Silos y Santo Domingo de la Calzada, compitiendo en la liberación de cautivos ${ }^{6}$. Mas con los datos con que contamos es difícil saber dónde empezó a correr esta especie de milagros, vinculados a unas gallinas.

No sabemos cuánto tiempo perduraron las gallinas en el monasterio, pero parece ser que en 1736 aún correteaban por los claustros, según testimonio del Padre Sebastián de Vergara:

Recogieron los monges el perro, gallo y gallina. De el perro, como era solo, no se pudo conservar la casta; consérvase oy la de el gallo y gallina. Su color es blanco, sus pies amarillos, su habitación los claustros y su jardín. Van a comer a refectorio, adonde acuden cuando tocan la campana, y de ordinario más puntuales que los monges, de cuyas manos toman la comida.

Véase sobre este particular Calavia, 2002, pp. 97-100. 
Venéranlas todos casi como reliquia y las llaman las gallinas de el

Santo (Vergara, 1736, pp. 67-68).

Todavía hoy los monjes conocen como gallinero del Santo los restos de la antigua sala capitular, porque es tradición que allí era donde se recogían estas aves. Uno de los cuadros de la capilla del Santo, obra del pintor mercedario Fray Gregorio Barambio entre 1745 y 1749, representa el milagro del $\mathrm{arca}^{7}$. En cuadros de la iglesia parroquial de Cañas (La Rioja), pueblo natal de Santo Domingo de Silos, y de San Millán de la Cogolla y en un dibujo del Museo del Prado se conservan representaciones de este suceso ${ }^{8}$.

Con los datos conocidos, es difícil precisar de qué raza eran las gallinas del Santo; de entre las veintidós razas autóctonas españolas ninguna hay que sea totalmente blanca ${ }^{9}$. La gallina blanca broiler, tan común hoy día, es un híbrido americano desarrollado a partir de $1930^{10}$.

Como hemos dicho, la Historia milagrosa de Ruiz de Montiano permaneció inédita, aunque fue muy utilizada por los biógrafos posteriores de Santo Domingo de Silos, algunos de los cuales imprimieron sus respectivas obras. Fue el primero el Padre Ambrosio Gómez de Salazar, monje de San Millán de la Cogolla ${ }^{11}$, quien en 1653 dio a luz El Moysen segundo nuevo redentor de España N. P. Sto. Domingo Manso (aclamado hasta aora santo Domingo de Silos). El segundo fue el Padre Juan de Castro, monje de Silos ${ }^{12}$, que en 1688 imprimió su propia biografía de Santo Domingo: El glorioso thaumaturgo español, redemptor de cautivos, Santo Domingo de Silos. Ambos traen el milagro de forma muy similar, pues beben los dos de la misma fuente. Sustancialmente sus relatos en nada se diferencian del de Ruiz de Montiano, salvo en dos detalles: ambos no dudan ya de la existencia de un arca de piedra, y Juan de Castro coloca un perro junto al gallo y la gallina, como ya hacía el frontal pintado del siglo XV, que arriba mencionamos. Colocamos en paralelo los dos relatos, para que se vean fácilmente sus semejanzas. Distribuimos el texto en párrafos para mayor comodidad:

Palacios, 2006, p. 59.

Gutiérrez, 2003, pp. 506-507.

Fernández Rodríguez, 2009, pp. 620-686.

Debo estas apreciaciones a mi buen amigo, el Doctor César favier Palacios Palomar.

Véase sobre este monje Vivancos, $2011 b$.

Véase sobre élVivancos, 2010. 


\section{Gómez, 1653, pp. 278-279}

Estimaua mucho vn moro a vn captiuo, porque de su arte tiraua no pocos intereses cada día.

En aquellas edades temían a Santo Domingo los sarracenos tanto que ninguno se fiaua de la profundidad de la cárcel ni del graue peso de las cadenas para la seguridad de sus esclauos.

Determinóse pues a poner de noche en su aposento al christiano dentro de una arca de piedra; dormía sobre ella el amo, y como tenía pesado el sueño puso vn gallo y gallina a su cabeçera, porque si el Santo venía por el captiuo, con el ruido que estas aues hazen, viendo a vna persona a deshora, despertasse.

¡Qué guardado le tiene! Porque no se le lleuen, le aflige. ¡Ha, cruel! Aun las caricias de los bárbaros son rigores. Temía Herodes que diesse la muerte a Juan la muger con quien estaua diuertido y con prisiones le atormentaua en la cárcel. Quando piensa que le agasaja, le martiriza; matan los crueles y entienden que lisongean.

Con esta que presumió seguridad se durmió. Pero, iqué caso tan raro! Moro, captiuo, arca y gallinas

\section{Castro, 1688, pp. 206-207}

Cierto moro tenía vn cautivo christiano a quien estimava en mucho por serle de grande vtilidad e interés, y como Santo Domingo tenía tanto nombre y fama, assí en Berbería como en otras partes, de que se llevava los cautivos, no avía moro que no viviesse temeroso y con grandes sobresaltos para guardar los suyos.

Este moro, pues, discurrió vna traça a su parecer famosa y muy segura, y algo parecida a la antecedente, para que el Santo no le llevasse su cautivo. Metiólo de noche en vna arca grande de piedra (porque ni los grillos ni las cadenas, ni los más profundos calaboços le parecían bastantes para librar de las manos del Santo a su cautivo). Ponía en su aposento el arca y armado de punta en blanco dormía sobre ella el moro; y por quanto tenía el sueño algo pesado, atava vn perro al arca y junto a su cabeçera ponía vn gallo y vna gallina, para que al tiempo que Santo Domingo viniesse por el cautivo le dispertassen el ladrido del mastín y el ruido que estas aves hazen quando ven alguna persona a deshora, y con esso pudiesse defender a su cautivo.

Esto discurría el moro y esto 
trasladó aquella noche Santo Domingo a su monasterio de Silos. Las campanas del monasterio le despertaron a la mañana y, hallándose en la iglesia, dio vozes.

Baxaron del coro los monges, vieron al moro turbado, sacaron de la arca de piedra al captiuo, recogieron el gallo y la gallina, que hasta oy se van conseruando en el monasterio para memoria perpetua del sucesso, para honra de Dios y gloria de nuestro Santo.

En el arca están aora las cenizas del obispo de Sidonia, Don Luis Méndez, hijo professo de Silos, en el crucero de la iglesia; al lado de la epístola yaze. executava de noche, pero salióle en vano su discurso y cuydado, porque estando vna noche dormido sobre el arca con toda esta prevención y máquina, llegó Santo Domingo al aposento y de un buelo trasladó a su monasterio de Sylos desde Berbería al moro, al cautivo, a la arca, perro, gallo y gallina. $\mathrm{Y}$ el primer ruido que sintió el moro no fue el que él pensó, sino el de las campanas del monasterio, que le dispertaron al amanecer. Hallóse, pues, a las puertas de la iglesia, dio vozes $y$, preguntando qué cencerros eran aquellos, le respondió el cautivo que estava dentro de su arca: «No son cencerros, sino campanas de christianos».

Baxaron los monges a las vozes, abrieron las puertas de la iglesia y, viendo el prodigio y toda aquella máquina de moro armado, perro, gallo y gallina, dieron las acostumbradas gracias a nuestro Señor. Sacaron del arca al cautivo y el moro quedó atónito sin saber lo que le avía sucedido. $Y$ es tradición que se bautizó a vista de tan estupendo milagro y que gastó lo restante de su vida en servicio del monasterio. Recogieron los monges el gallo y la gallina, cuya casta, como he dicho, se conserva oy día para perpetua memoria de tan assombrosa maravilla y para honra de Dios y gloria de su siervo Santo Domingo de Sylos. 
El perro murió y el arca de piedra está en la iglesia del monasterio junto a la sacristía, y en ella descansan las ceniças del señor Don Fray Luis Méndez, obispo que fue de Sidonia, hijo professo y abad de aquella casa y prior de la de San Martín de Madrid, porque por aquellos años no era abadía la casa de San Martín, sino priorato de Sylos

Ambrosio Gómez, quizás por no ser monje de Silos, nada dice sobre la descendencia del gallo y la gallina. Juan de Castro las menciona, pero viene a decir más o menos lo mismo que su predecesor, Gaspar Ruiz de Montiano, añadiendo por su cuenta que venían de Berbería:

En el real monasterio de Santo Domingo de Sylos se conserva hoy día vna casta de gallinas que ha más de quatrocientos y tantos años que vinieron de Berbería; son blancas como vna nieve y tienen las paticas amarillas como la cera. Son tan mansas y domésticas que se entran en el refitorio a comer con los monges en oyendo la campanilla. Allí comen y beben en medio del refitorio y algunas vezes, si se descuydan los religiosos en echarlas de comer, se suben a las mesas a pedirlo y lo toman de la mano. Su habitación común por el día es el claustro, y de noche se recojen a vna parte que tienen señalada junto al refitorio para dormir. Esta casta de gallinas trae su origen y descendencia de vn gallo y de vna gallina que traxo el Santo de Berbería (como aora diré), y en tantos años jamás ha faltado gallo y gallina en el monasterio que publiquen el milagro (que no es pequeña maravilla). Ellas se van conservando y procreando, y toda la gente de aquella tierra las estima en mucho, y las llama las gallinas del Cuerpo Santo, y muchas mugeres devotas suelen pedir los huevos para echarlos a sus gallinas y criar las del Cuerpo Santo (Castro, 1688, pp. 205-206).

Según el relato de Pero Marín ${ }^{13}$, Santo Domingo había liberado a cautivos cristianos allende el mar, concretamente de Arcila, Tánger y

$13 \quad$ Anton, 1988, pp. 53; 85; 106; 135; 137-139. 
Ceuta, por lo que a los monjes de Silos no podía extrañar un nuevo milagro, ocurrido en algún lugar de Berbería. No sabemos por qué vías el relato debió de llegar al monasterio jerónimo de Santa María de Guadalupe (Cáceres), en cuyo claustro se halla un cuadro del siglo XVII, que representa un milagro similar, donde se dan cita cautivo, arca, perro y moro, y que lleva la siguiente leyenda:

Eran tantos los cautiuos que nuestra Señora sacaua de poder de infieles que ya no hauía prisiones ni guardas para tenerlos seguros. Parecióle a vn moro que aseguraua vn christiano cautiuo que tenía con vna diligencia extraordinaria. Encerróle en vna arca, púsose a dormir encima con vn perro al lado, y quando despertó se hallaron a vista desta santa casa, el cautiuo libre, él espantado y el perro y la arca por testimonio del milagro.

Pero hay constancia impresa del milagro en 1631, esto es, años antes de que Gómez y Castro dieran a los tórculos sus respectivas biografías de Santo Domingo de Silos, pero unos veinte años después de que Ruiz de Montiano escribiera la suya. Se halla en la Venida de la soberana Virgen de Gvadalvpe a España, del monje jerónimo Fray Diego de Montalvo, obra impresa en Lisboa en 1631, y en la que existe una gran coincidencia de fondo en el milagro acaecido a Diego Sotelo, natural de Évora, quien fue hecho preso en la ciudad de Ceuta y liberado en 146314 . En este caso, el propio cautivo advierte al moro, su señor, que la Virgen de Guadalupe

le auía de sacar muy presto de sus manos y prisiones. Mandó el moro para assegurarse de la amenaza de su captiuo hazer vn arca de fortíssima madera, aforrada con planchas y barrotes de hierro, y seys pestillos con sus llaues seguras, y metió dentro aherrojado con grillos y fuertes esposas a su captiuo. Cerró por su mano las llaues y puso vn perro junto al arca, y él sobrella por guarda mejor y más cuydadosa, y apostándoselas al deuoto captiuo le dixo: «Ea, veamos, perro, cómo essa que tú adoras por milagrosa y en cuyo fauor en vano por esta vez esperas, te sacará de mi poder y lleuará a la maldita tierra de christianos». Llamando el captiuo a la celestial y gloriosa Virgen de Guadalupe, por respuesta dixo [...]. Sucedió a esto la obra más rara que se ha visto y con que se admira y pasma el más deuoto corazón: que súbitamente captiuo, arca, moro y perro amanecieron de la manera como estauan en la mazmorra en este sagrado templo,

14 El milagro también lo recoge San fosé, 1743, p. 81. 
donde todo sirue de tropheo singular, en que se venera su milagrosa autora [...]. Turuóse el moro en presencia de la Magestad soberana sin tener libertad en sus acciones y sin poder en gran rato quitar las llaues de la cinta para dar puerta al dichoso Sotelo, deseosíssimo ya de verse en los ojos celestiales de la princesa de los ángeles. Abrió el padre portero el arca más milagrosa que la de Noé en el diluuio y presentó los huéspedes, que con dicha de todos traýa a su santa casa la omnipotencia de la Reyna del cielo. Obró la fuerça desta rara y singular marauilla en el alma del moro efectos soberaníssimos, los quales le obligaron a dexar la descomulgada y burladora religión en que se auía criado, y perseueró como agradecido en el seruicio de la Madre de Dios (Montalvo, 1631, fols. 20-21).

Son evidentes las similitudes con el milagro de Santo Domingo de Silos, y todo obliga a pensar en el silense como fuente del guadalupano, si es que ambos no derivan de una fuente común, ya que, como hemos visto, al menos desde el siglo XV hay testimonio, aunque sea solo gráfico, del milagro ampliado. Este traspaso de portentos de un santo a otro es bastante habitual, y, sin ir más lejos, en la biografía de Santo Domingo de Silos, escrita por su discípulo, tenemos un ejemplo, pues Grimaldo atribuye al santo abad un milagro tomado casi literalmente de Gregorio Magno, mientras que Ruiz de Montiano le adjudica otro que pertenecía a San Millán de la Cogolla ${ }^{15}$.

No es solo la Virgen de Guadalupe quien se dedica a rescatar cautivos de forma tan maravillosa. Tenemos un relato publicado en 1726 por el jesuita Juan de Villafañe, que atribuye el mismo caso a la Virgen del Camino, en León:

Pero no puedo omitir el portento singular que a pocos años de aparecida obró su Magestad con un cautivo, para cuya memoria se conserva aún hoy en su iglesia una arca grande y una cadena de fuertes eslabones de hierro, que servían para lo que dize el caso, que es el siguiente, referido casi con las mismas palabras que se leen en una tabla colocada en parte pública de la iglesia, lo que también observaré en los demás milagros.

Hallábase Alonso de Ribera, vezino de Villamañán, cautivo en Argel, en poder de un moro que se llamaba Alcazaba, y como padeciesse grandes trabajos en tan duro cautiverio invocaba muchas

15 Vivancos, 2003, pp. 233; 249. 
vezes a la sagrada imagen de nuestra Señora del Camino, de que, sabidor el moro, temiendo que le avía de librar y sacar de su poder esta poderosa Señora, ligándole con una fuerte cadena le encerró en una arca una noche, y poniéndose el moro también, para mayor seguridad, encima, juzgaba con tales precauciones tenerle seguro. Quedóse en esto dormido el moro y nuestra Señora del Camino, aviendo oído la oración del esclavo, trasladó de la manera que su Magestad sabe a su devoto con la cadena, arca y moro encima de ella a la puerta de su santuario, en donde fue todo visto por la mañana, y el moro fuera de sí por la novedad, sacando el cautivo del arca, reconoció por su dicho ser aquella la iglesia de nuestra Señora del Camino, a quien se avía encomendado; y visto tan prodigioso sucesso, el moro se convirtió a la religión christiana y los dos se quedaron a servir en su santuario, en donde tuvieron dichosa muerte. Sucedió este raro y maravilloso caso año de 1522 (Villafañe, 1726, p. 139).

Aunque aquí no hay perro, sí que se dan las otras circunstancias coincidentes con los otros relatos, cautivo, arca, moro, cadenas. Tanto en Silos como en Guadalupe, y ahora en León, el moro se convierte y se queda el resto de su vida al servicio del santuario. El arca de madera aún se halla en el santuario leonés.

Hemos encontrado un último testimonio del portento en la villa soriana de Almenar, atribuyéndolo a la Virgen de la Llana, pero en este caso el milagro no cuenta con fuentes escritas tempranas ${ }^{16}$. Consta en un inventario parroquial de 1704 que ya por entonces, en la sacristía de la ermita de la Virgen de la Llana, se hallaba un arca de madera de roble, «junto con unos grillos, cadenas, esposas y colleras de yerro, que son del milagro ${ }^{17}$ », y que aún se conservan hoy día. Pero hay que esperar hasta 1860 para encontrar impresa una narración novelada del milagro, y hasta 1901 para encontrar otra en verso. El cautivo era natural de Peroniel y en época desconocida se vio libre gracias a la intercesión de la Virgen de la Llana de su prisión en Argel; el milagro incorpora arca, cautivo, moro y cadenas, pero como en León, aquí tampoco hay perro. El prodigio se halla representado en un medallón del retablo del santuario de la Virgen, hecho en $1799^{18}$.

16 Para lo que sigue remitimos a De Miguel, 1998, pp. 123-142.

Ibidem, p. 136.

$18 \quad$ Fotos en ibidem, pp. 57; 133. 
En conclusión, un milagro obrado por intercesión de Santo Domingo de Silos en 1285 parece haber sido reelaborado en sucesivas etapas desde el siglo XV en su propio monasterio, con la finalidad de explicar el origen de una raza especial de gallinas que se criaban en el monasterio. Sin referencia a las aves, en distintos momentos los santuarios marianos de Nuestra Señora de Guadalupe, Virgen del Camino de León y Virgen de la Llana en Almenar se apropiaron del milagro y lo atribuyeron a la Virgen María en sus particulares advocaciones.

\section{Bibliografía}

K.-H. ANTON, (1988), Los «Miraculos romançados» de Pero Marín. Edición crítica, introducción e índices, Abadía de Silos (Stvdia Silensia XIV), pp. 119-120.

O. CALAVIA SÁEZ, (2002), Las formas locales de la vida religiosa. Antropología e historia de los santuarios de La Rioja, Madrid, CSIC.

J. DE CASTRO, (1688), El glorioso thaumaturgo español, redemptor de cautivos, Santo Domingo de Silos, hijo del patriarca San Benito, abad y confesor. Su vida, virtudes y milagros. Noticia del real monasterio de Sylos y sus prioratos, Madrid, Melchor Álvarez.

M. FERNÁNDEZ RODRÍGUEZ et al. (coords.), (2009), Guía de campo de las razas autóctonas españolas, Madrid, Ministerio de Medio Ambiente.

A. GÓMEZ, (1653), El Moysen segundo nuevo redentor de España N. P. Sto. Domingo Manso (aclamado hasta aora santo Domingo de Silos), su vida, sus virtudes y milagros antes y después de su muerte, Madrid, J. Martín de Barrio.

J. GONZÁlEZ TEXADA, (1702), Historia de Santo Domingo de la Calzada, Abrahán de la Rioja, Madrid, Vda. de M. Álvarez.

I. GUTIÉRREZ PASTOR, (2003), "Iconografía de Santo Domingo de Silos", en Silos. Un milenio. Actas del Congreso Internacional sobre la Abadía de Santo Domingo de Silos (IV. Arte), Silos, (Stvdia Silensia XXVIII), pp. 455-528. Llana, Soria.

L. DE MIGUEL FERNÁNDEZ, (1998), Almenar y la Virgen de la

D. DE MONTALVO, (1631), Venida de la soberana Virgen de Gvadalvpe a España, sv dichosa invención y de los milagrosos fauores que ha hecho a sus deuotos, vol. I, Lisboa, P. Craesbeeck.

C. J. PALACIOS PALOMAR, (2006), Tesoros de Silos. Catálogo artístico del monasterio de Santo Domingo de Silos, Silos, (Stvdia Silensia series maior $\mathrm{V}$ ). 
F. DE SAN JOSÉ, (1743), Historia universal de la primitiva y milagrosa imagen de Nra. Señora de Guadalupe, Madrid, A. Marín.

V. VALCÁRCEL, (1982), La «Vita Dominici Siliensis» de Grimaldo. Estudio, edición crítica y traducción, Logroño, Instituto de Estudios Riojanos.

S. DE VERGARA, (1736), Vida y milagros de el thaumaturgo español, Moysés segundo, redemptor de cautivos, abogado de los felices partos, Santo Domingo Manso, abad benedictino, reparador de el real monasterio de Silos, Madrid, H. de F. del Hierro.

J. DE VILLAFAÑE, (1726), Compendio histórico en que se da noticia de las milagrosas y devotas imágenes de la reyna de los cielos y tierra, María santíssima, que se veneran en los más célebres santuarios de Hespaña, Salamanca, E. García de Honorato.

M. C. VIVANCOS, (2003), "Domingo de Silos: historia y leyenda de un santo", en Silos. Un milenio. Actas del Congreso Internacional sobre la Abadía de Santo Domingo de Silos (II. Historia), Silos (Stvdia Silensia XXVI), pp. 223-263.

M. C. VIVANCOS, (2010), “Castro y Zaguirre, Juan de”, en Diccionario biográfico español, vol. XII, Madrid, Real Academia de la Historia, p. 713.

M. C. VIVANCOS, (2011a) "Domingo de Silos, Santo", en Diccionario biográfico español, vol. XVI, Madrid, Real Academia de la Historia, pp. 478-479.

M. C. VIVANCOS, (2011b), “Gómez de Salazar, Ambrosio”, en Diccionario biográfico español, vol. XXIII, Madrid, Real Academia de la Historia, pp. 547-548.

M. C. VIVANCOS, (2012), "Marín, Pedro", en Diccionario biográfico español, vol. XXXII, Madrid, Real Academia de la Historia, p. 557. 


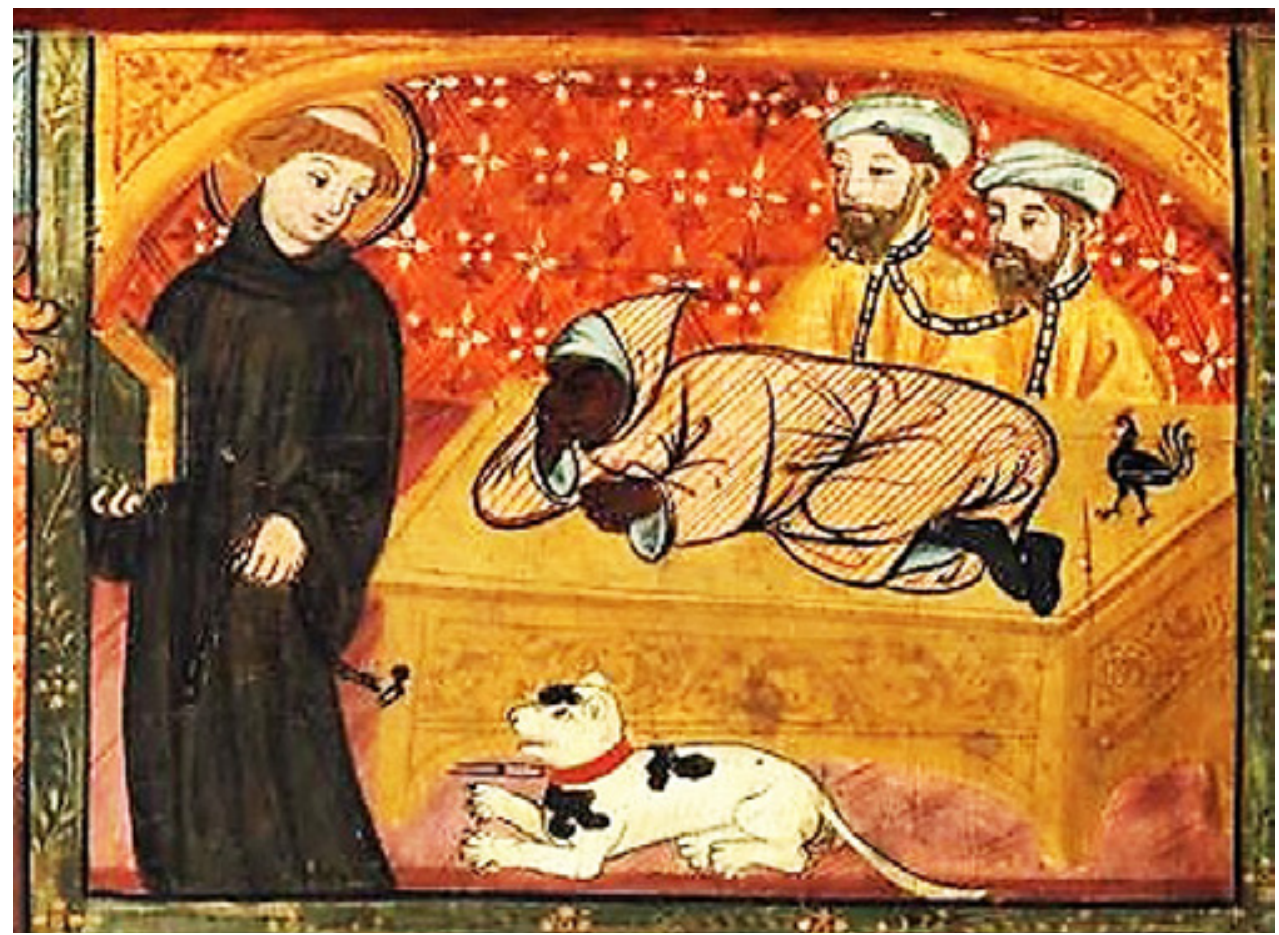

Fig. 1. Detalle del frontal de Santo Domingo de Silos, del Museo de Bellas Artes de Bilbao, primera representación del milagro del arca (ca. 1400).

\section{fy}
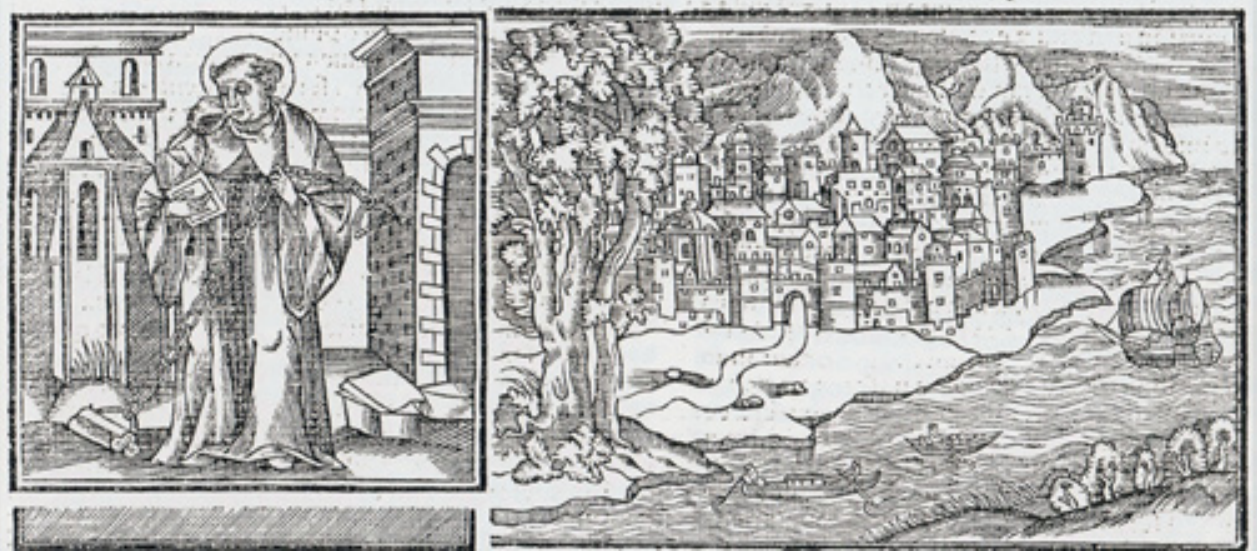

Fig.2. Santo Domingo de Silos con sus yerros, según grabado xilográfico que aparece en la obra de Fray Pedro de la Vega, Flos sanctorum, Sevilla, F. Gutiérrez, 1569. 


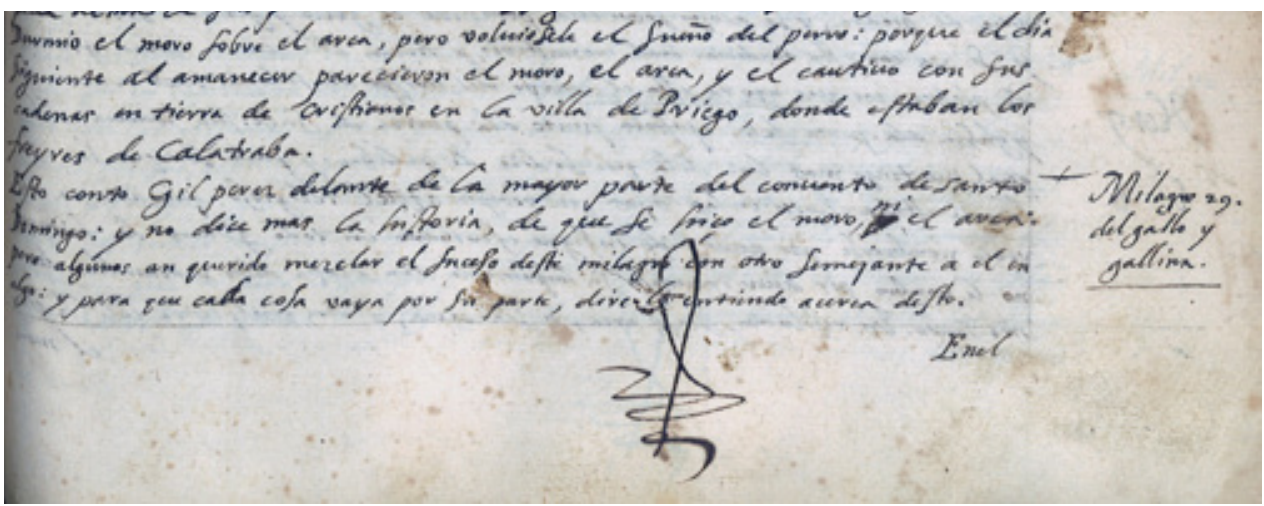

Fig.3. Comienzo del milagro del arca en el manuscrito de Fray Gaspar Ruiz de Montiano

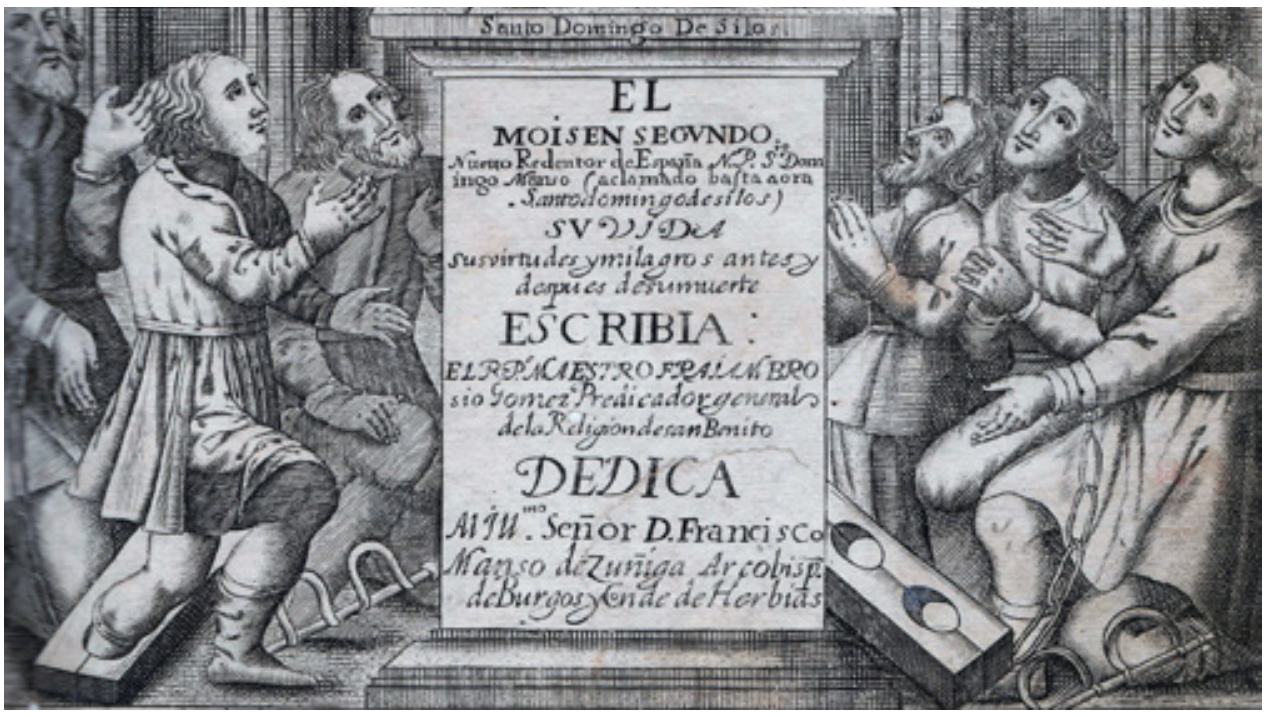

Fig. 4. Grupo de cautivos, según grabado de Gregorio Frosman, en la obra de Fray Ambrosio Gómez, El Moysen segundo, Madrid, f. Martín de Barrio, 1653. 


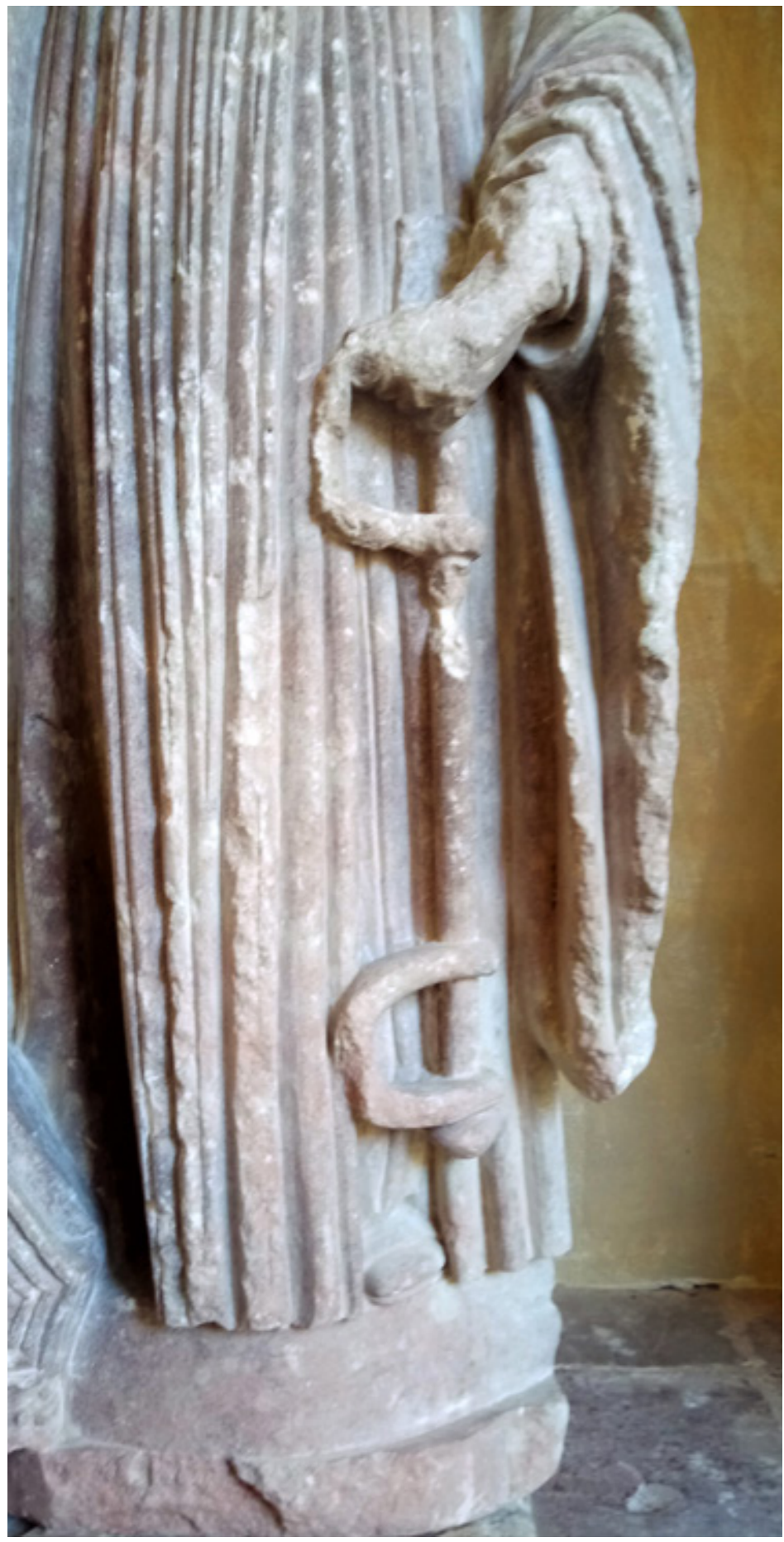

Fig.5. Detalle de los grillos de una escultura de Santo Domingo de Silos, de mediados del siglo XVII, en el monasterio de San Millán de la Cogolla. 


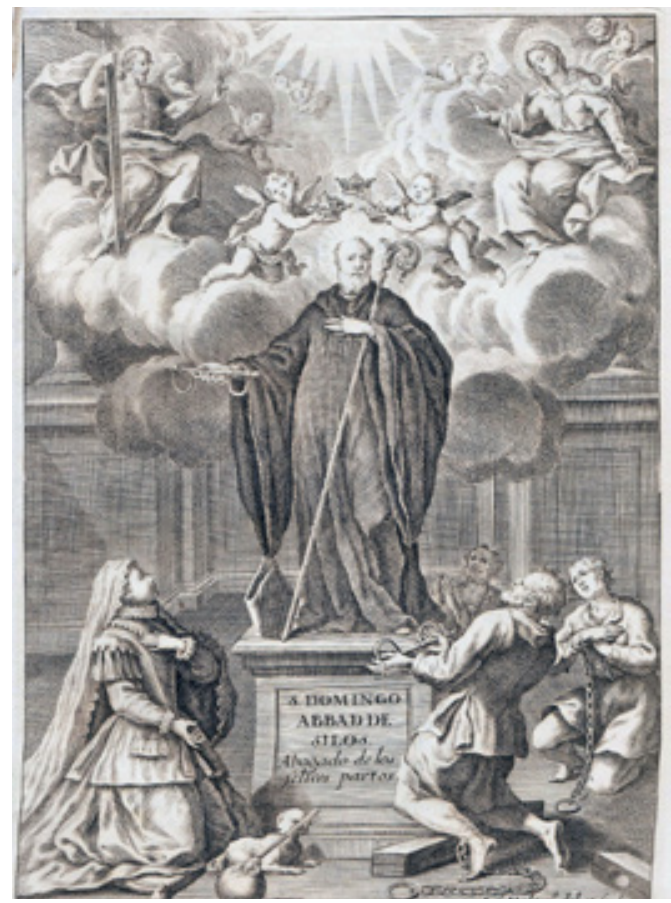

Fig. 6. Santo Domingo de Silos, según grabado de fuan B. Palomino en la obra de Fray Sebastián de Vergara, Vida y milagros de el thaumaturgo español, Madrid, H. de F del Hierro, 1736.

Fig.7. Detalle del cautivo, del cuadro del monasterio de Nuestra Señora de Guadalupe

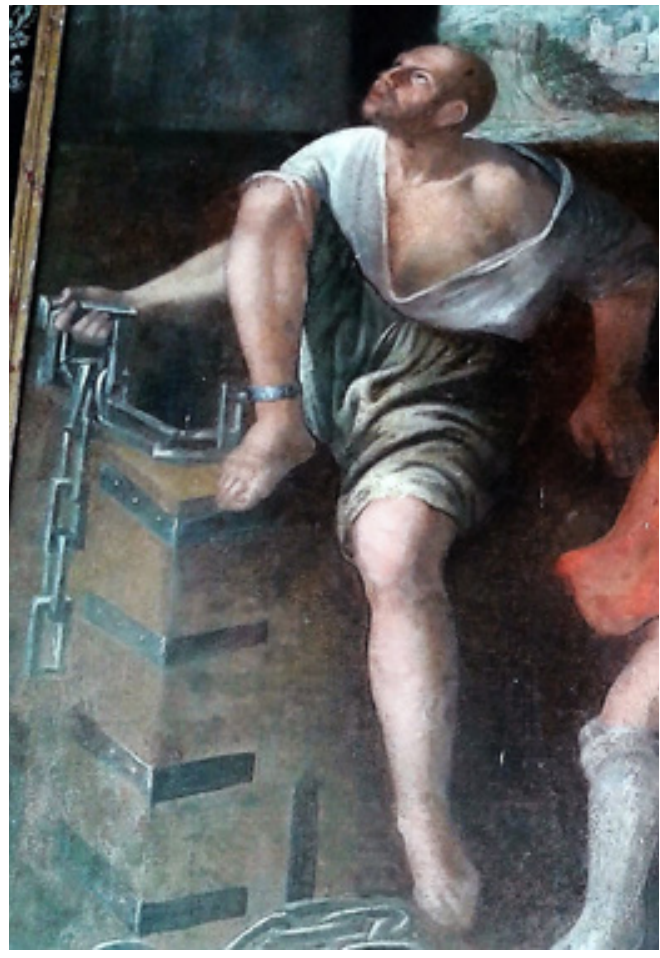

